\title{
Differential Effect of Acute Stress on Visuospatial Working Memory and Sexual Motivation in Male Rats
}

\author{
Marisela Hernández-González*, Enrique Hernández-Arteaga, \\ Mayra Linné Almanza-Sepúlveda, Miguel Ángel Guevara \\ Instituto de Neurociencias, Universidad de Guadalajara, Guadalajara, Jalisco, México \\ Email: ${ }^{*}$ mariselh@cencar.udg.mx
}

Received 15 May 2015; accepted 4 July 2015; published 7 July 2015

Copyright (C) 2015 by authors and Scientific Research Publishing Inc.

This work is licensed under the Creative Commons Attribution International License (CC BY). http://creativecommons.org/licenses/by/4.0/

(c) () Open Access

\begin{abstract}
Working memory is an executive function that is highly dependent on the functioning of the prefrontal cortex. Several studies using food or drink as rewards have demonstrated that rats are capable of performing tasks that involve working memory. Sexual behavior is another highlyrewarding, motivated behavior that has proven to be an efficient incentive in classical operant tasks. Considering that both sexual behavior and working memory are sensitive to the effects of stress, the aim of this study was to determine the effect of acute stress on visuospatial working memory during a sexually-motivated task (a nonmatching-to-sample task in a T-maze) in male rats. Thirty-two male Wistar rats were trained in the T-maze using sexual interaction (intromission and ejaculation) as a reinforcer during a 4-day training period (training sessions held every 4th day). On the basis of their performance, the rats were classified as good-learners $(n=12)$ and bad-learners $(n=20)$, and on the fifth day, 6 good-learners and 10 bad-learners were subjected to stress using the cold water immersion model (CWI, $15^{\circ} \mathrm{C}$ ) for 15 minutes before they were evaluated in the T-maze. The remaining rats made up the control group (i.e., they performed the task without previous stress). Results showed that acute stress by CWI improved working memory in the bad-learners but did not affect the performance of the good-learners, although in both groups (good- and bad-learners) stress decreased the sexual motivation to perform the task. It is probable that the increased levels of corticosterone in the stress situation could activate glutamatergic transmission in the prefrontal cortex, thus facilitating working memory and, simultaneously, decreasing testosterone levels, which exerts a negative effect on sexual motivation in these male rats.
\end{abstract}

${ }^{*}$ Corresponding author.

How to cite this paper: Hernández-González, M., Hernández-Arteaga, E., Almanza-Sepúlveda, M.L. and Guevara, M.Á. (2015) Differential Effect of Acute Stress on Visuospatial Working Memory and Sexual Motivation in Male Rats. Journal of Behavioral and Brain Science, 5, 221-230. http://dx.doi.org/10.4236/jbbs.2015.57023 


\section{Keywords}

\section{Stress, Working Memory, Sexual Behavior}

\section{Introduction}

Stress is a biological mechanism through which the body attempts to regain homeostasis when it is affected by internal and/or external adverse forces (stressors) [1]. According to its temporality, stress can be classified as acute or chronic [2]. Acute stress, also known as eustress, is generally associated with short, controllable stressors and hence acts for periods from a few minutes to a few hours [2] [3]. It has been reported that acute stress may affect executive functions, such as working memory [4], and there is theoretical evidence that supports a relationship between stress and working memory.

However, some authors report that acute stress impairs working memory [5] [6], while others, to the contrary, postulate that it may facilitate working memory [7]-[9].

Different studies have demonstrated that rodents are capable of performing diverse tasks that involve important executive functions, such as flexibility, attention and working memory [10]-[12]. Most of the research that has evaluated working memory in rats has used food or drink as rewards; however, sexual behavior (intromission and ejaculation) has also proven to be a highly-rewarding motivated behavior that has been used efficiently both as an incentive and as a reward [13]-[18] in the same way as other primary reinforcers [19].

In a recent study, we reported a paradigm to evaluate working memory in rats using sexual behavior as a reward (a delayed task with alternation to the sample: 4 daily copulatory series leading to ejaculation during 4 days of recording, alternated every 4 days). Results showed that the male rats in that experiment manifested an appropriate learning curve and maintained their sexual motivation throughout the task days [20]. Using the same paradigm, we also reported that the activity of the medial prefrontal cortex (mPFC) changes in relation to the working memory processes involved in this sexually-motivated task [18].

Both sexual behavior and working memory are sensitive to stress [6] [21], the effects of which, as is wellknown, vary according to the kind and temporality of the stressors involved [5] [6] [22]-[26]. For example, there are reports that acute and chronic immersion in cold water drastically alters the motivational component and copulatory performance, and that immobilization alters mount frequency and hit rate, while electrical shocks applied to the feet affect the copulatory parameters only when exposure is chronic [21]. This suggests that the effect of stress on sexual behavior depends on the nature and, in some conditions, duration, of the stressor.

Considering that stress can affect both working memory [5]-[7] [26]-[28] and sexual behavior [21] [29], the aim of this study was to determine the effect of acute stress (using the model of stress caused by cold water immersion) on visuospatial working memory in male rats during the performance of a sexually-motivated task.

\section{Methods}

\subsection{Subjets}

A total of 32 sexually-expert male Wistar rats weighing between 280 and $380 \mathrm{~g}$ were used. The rats were maintained under an inverted light/dark cycle $(12 \mathrm{~h} / 12 \mathrm{~h})$ at a temperature of $20^{\circ} \mathrm{C}-22^{\circ} \mathrm{C}$ with water and food ad libitum. Also, a group of 20 female rats was treated with estradiol benzoate $(0.5 \mu \mathrm{g} /$ every other day), and progesterone $(500 \mu \mathrm{g} / \mathrm{sc})$, with the latter being administered 4 - 6 hours before they were used as the rewarding stimulus in the copulatory tests of all experimental situations.

\subsection{Sexual Interaction Test}

All male rats participated in at least 3 trials of sexual behavior at 3-day intervals during a training phase before the experiment began. By the end of that phase, all the males used in the study exhibited consistent parameters of sexual activity, including intromission within $20 \mathrm{~s}$ of presentation of the female, ejaculation within 10 min of first intromission, and re-initiation of copulation within $10 \mathrm{~min}$ of first ejaculation. All behavioral tests were conducted between 10:00 and 13:00 h; i.e., during the dark phase. Animal care and all procedures involving the rats were approved by the Institutional Animal Care and Use Committee at the Institute of Neuroscience, in accordance with NIH specifications. 


\subsection{Behavioral Test}

\subsubsection{T-Maze}

A nonmatching-to-sample working memory task with a sexual incentive was applied using a T-maze made of wood. A start-box cage was attached to the initial segment of the T-maze, and at the end of each arm a similar cage was placed containing a receptive female used as the rewarding stimulus. Access to the cages was restricted by guillotine doors. The objects and tester in the experimental room served as spatial signals. The rats were allowed to explore the maze freely for a 20 -min period 1 day before the training phase in order to become habituated to this environment. As in previous studies [18] [20], working memory training in this experiment was performed every 4 th day until reaching a total of 4 training days. On each occasion, the rats were subjected to 4 copulatory series, each one involving various training trials.

During the working memory tests, a receptive female was placed in each cage at the end of the two arms of the maze. To sexually-motivate the male rats, each one was allowed one intromission with a receptive female in the start-box before training began. Immediately after this initial motivation, a male rat was placed in the startbox and the first trial was conducted: i.e., the guillotine door was opened and the rat was subjected to a forced sample run in which only one arm of the maze was open (pseudo-randomly assigned). The door at the end of that arm was removed and one intromission with the receptive female was allowed. The male rat was then removed and returned to the start-box. Subsequently, the door was opened for a test run in which both arms were open. In the test run, the male rat was rewarded by allowing it one intromission with the receptive female, but only if it chose the opposite arm to the one it had visited in the sample run (nonmatching-to-sample procedure). Thus, each trial consisted of one sample run and one test run, with an inter-trial period of $10 \mathrm{~s}$. A series of trials was considered complete when the rat reached ejaculation. Hence, the number of trials in the copulatory series varied according to those performed before each rat ejaculated. After the first and second copulatory series (when the first and second ejaculations occurred), the rats were allowed a rest period of $30 \mathrm{~min}$, while between the third and fourth copulatory series, a rest period of 60 min was given.

After the 4-day training period, the performance of the rats was evaluated and they were classified in 3 groups (good-, medium- and bad-learners). The bad-learners group $(\mathrm{n}=12)$ included those with a percentage of correct responses (i.e., the number of times the rat entered the correct arm in the test run in each copulatory series in proportion to the total number of trials) below $80 \%$ on days 1 and 2 of training (acquisition phase), and a percentage of correct responses also below $80 \%$ on days 3 and 4 of training (maintenance phase). Also considered bad-learners were those rats that were unable to realize 3 copulatory series with $100 \%$ of correct responses during the maintenance phase (days 3 and 4 of training). The good-learners group $(n=20)$ included the rats that achieved a percentage of correct responses below $80 \%$ in the acquisition phase but were able to attain $100 \%$ of correct responses in at least 3 copulatory series during the maintenance phase. The other rats (medium-learners, $\mathrm{n}=18$ ) did not meet the aforementioned criteria for bad- or good-learners and so were discarded. Thus, the subsequent procedure included only the good- and bad-learner groups.

Both good- and bad-learners were further divided into 4 sub-groups, and on day 5 ( 4 days after the 4th day of training) were again subjected to the working memory task. However, on that day half of the rats were stressed (stress group $=6$ good- and 10 bad-learners) while the other half was left undisturbed (control group $=6$ goodand 10 bad-learners) before beginning the T-maze test.

\subsubsection{Stress by Cold Water Immersion}

Subjects in the stress group ( $\mathrm{n}=16,6$ good- and 10 bad-learners) were placed in a tank of cold water (height $=$ $20 \mathrm{~cm}$; temperature $=15^{\circ} \mathrm{C}$ ), where they either swam or remained in an upright position keeping their heads above the water level. They remained in this situation for 15 min unless they sank. Immediately afterwards, the rats were removed from the tank of cold water and placed in a single box for $20 \mathrm{~min}$ before being subjected to 2 copulatory series in the T-maze following the procedure described above. The rats in the control group $(n=16$, 6 good-, and 10 bad-learners) were subjected to the same copulatory series but without exposure to the stressor.

\subsubsection{Behavioral Recording}

The SexyMater computer program [30] was used to record the rats' performance in the T-maze with sexual behavior as the reward. At task onset, the program showed a window with 10 numbered touch keys and a timer. Pressing each key—either by clicking or using a finger in the case of tactile computers screens -increased the corresponding counter by one. During execution of the T-maze task, the keys numbered 4, 5, and 6 were used. 
Onset latency was recorded with number 6, while numbers 4 and 5 were used to record the number of correct and incorrect responses, respectively. When the task concluded, the number 0 was pressed and the program closed the window.

\subsection{Statistical Analysis}

To assess the effect of acute stress on working memory, the study considered the percentage of correct responses on the final series of day 4 (representative of the maintenance phase of working memory) and the first series of day 5 (experimental phase: stress or control). The performance of each group on each day was compared using a Wilcoxon test, and between groups on each day was compared using a Mann-Whitney U test. The percentages of correct responses on the last series of day 4 vs. the first series of day 5 between the stressed rats (i.e., good- vs. bad-learners) were also compared using a Mann-Whitney U test.

To assess the effect of acute stress on sexual motivation, the mean value of onset latency (i.e., the time from the moment the male rat was placed in the start box until it reached the goal box) was used. The onset latencies in seconds from the last series of day 4 (representative of the maintenance phase) and the first series of day 5 (experimental phase: stress or control) were considered. Higher onset latency was interpreted as showing lower sexual motivation to perform the sexually-motivated task. Each group was compared using an ANOVA, followed by a post hoc Tukey test (to compare interaction among factors such as training days and groups).

For the stressed group, the percentage of correct responses and onset latency between the first (i.e., after stress treatment by cold water immersion) and second series (i.e., after ejaculation in the first trial) on day 5 were compared. The percentage of correct responses was compared using a Wilcoxon test, while onset latency was compared using a repeated measures t-student test.

\section{Results}

\subsection{Performance on the Working Memory Task}

The trained male rats were classified according to their behavioral performance in 3 groups, as explained above. The good-learners group had a higher percentage of correct responses in the maintenance phase (day 4; 81.162\% $\pm 7.784 \%$ ) than in the acquisition phase (day $1 ; 68.465 \% \pm 6.562 \% ; \mathrm{t}=-2.75 ; p=0.019$ ); while the bad-learners group showed no changes in the percentage of correct responses during the different training phases (day 1 , $62.771 \% \pm 4.026 \%$; day 4, 65.158\% \pm 5.798\%). The medium-learners were not considered in this analysis.

\subsection{Effect of Acute Stress on Working Memory}

\subsubsection{Good-Learners}

The good-learners (in both the stress and control groups) showed no differences in the percentage of correct responses between groups on any day (stress vs control on day $4 U=9.0, p(F)=0.1797$; and on day $5 U=17.00$, $p(\mathrm{U})=0.9372)$, nor did they exhibit changes among days [stressed good-learners group $(\mathrm{n}=6 ; \mathrm{W}=6.0, p(\mathrm{~W})<$ $0.2)$, control good-learners group $(\mathrm{n}=6 ; \mathrm{W}=7.0, p(\mathrm{~W})<0.2)$ ] (Figure 1(a)).

\subsubsection{Bad-Learners}

Only the stressed bad-learners group showed a higher percentage of correct responses on day 5 compared to day $4(\mathrm{n}=10 ; \mathrm{W}=1.0 ; p(\mathrm{~W})<0.003)$, and only on day 5 the stressed bad-learners showed a higher percentage of correct responses compared to the control group $(U=14.0, p(U)=0.0054)$ (Figure $1(b))$.

\subsection{Comparison among Stressed Groups}

The stressed bad-learners group presented a lower percentage of correct responses on day 4 (maintenance phase) compared to the stressed good-learners $(\mathrm{U}=4.5, p(\mathrm{U})=0.0067)$ and to the stressed bad-learners on day 5 . No differences between the stressed bad- and good-learners were found on day 5 (after stress treatment) $(U=23.5$, $p(\mathrm{U})=0.4528)$ (Figure 2).

\subsection{Effects of Stress on Sexual Motivation}

Intromission latency measured before performing the working memory test in the T-maze (i.e., after stress 


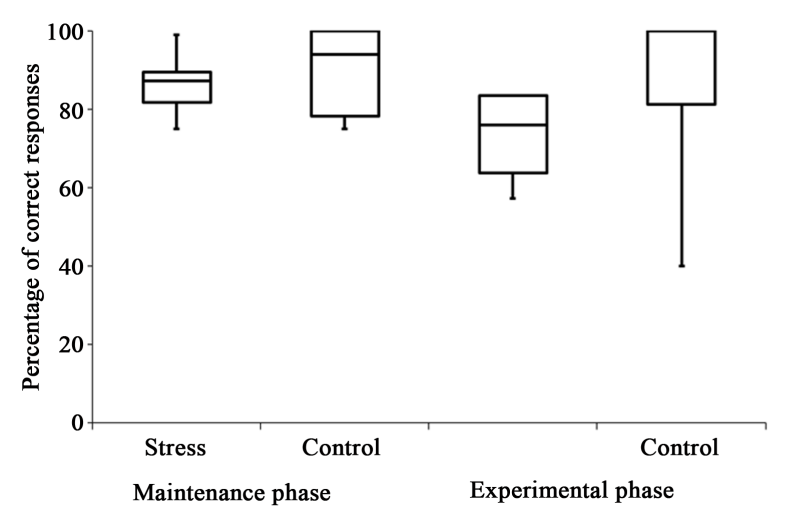

(a)

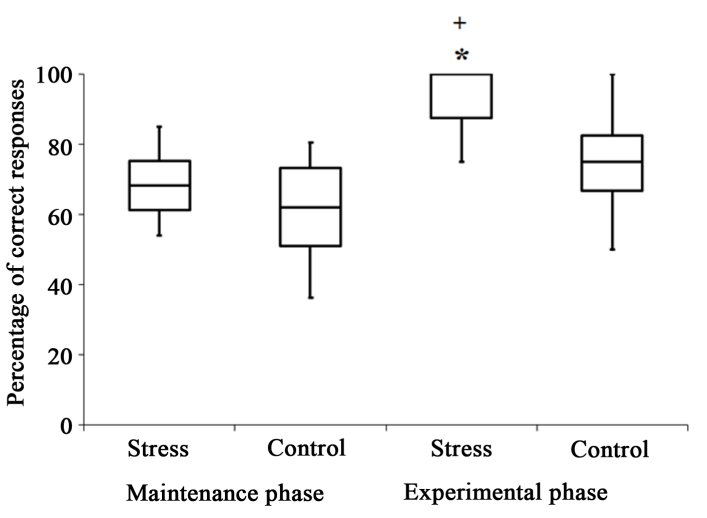

(b)

Figure 1. Median \pm inter-quartile range of percentage of correct responses during the nonmatching-to-sample task in a T-maze during the maintenance phase (day 4) and ex perimental phase (day 5), performed by (a) good-learners ( $n=6 /$ group) and; (b) bad-learners ( $\mathrm{n}=10$ /group). ${ }^{*} p<0.01$ compared to stressed group on day $4{ }^{+} p<0.01$ compared to control group on day 5 .

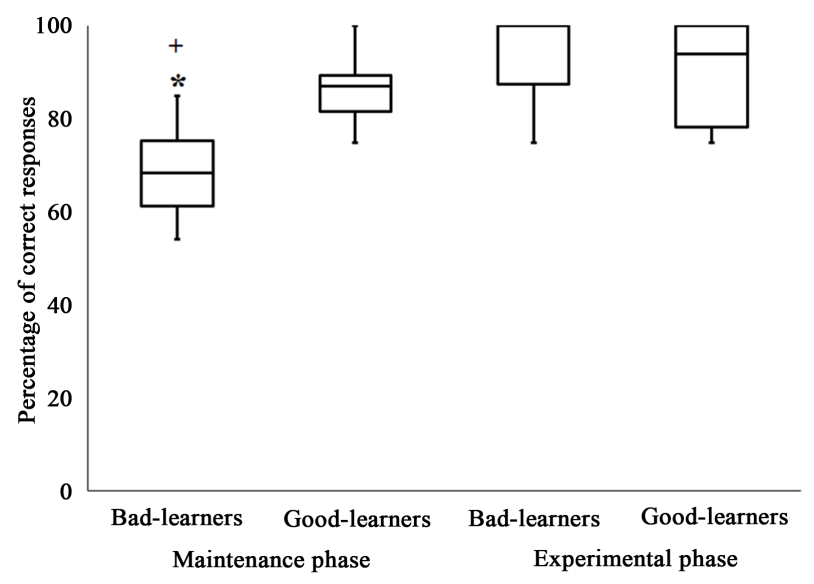

Figure 2. Median \pm inter-quartile range of percentage of correct responses during the nonmatching-to-sample task in a Tmaze during the maintenance phase (day 4) and experimental phase (day 5) performed by the subjects in the stressed goodand bad-learners groups. ${ }^{*} p<0.01$ compared to good-learners on day $4{ }^{+}{ }^{+} p<0.01$ compared to stressed bad-learners on day 5 .

treatment) on day 5 also presented significant differences between groups, as the stressed rats (both good- and bad-learners) exhibited a higher intromission latency (1904.375 sec \pm 329.03) than controls (16.938 sec \pm 28.616; $\mathrm{t}=11.47 ; p<0.0001)$.

\subsubsection{Good-Learners}

A significant difference in the interaction of onset latency over the different days and groups (stress and control; $\mathrm{F}=19.55, p(\mathrm{~F})=0.0013$ ) was obtained in both the stressed and control groups of good-learners. The stressed good-learner group exhibited a higher onset latency on day 5 (experimental phase) compared to day 4 (maintenance phase; $p<0.01$ ) as well as when compared to the control group, but only on day 5 ( $p<0.01$ ) (Figure 3(a)).

\subsubsection{Bad-Learners}

The bad-learners (both stressed and control) showed significant changes in the interaction of the onset latency over the different days and groups (stressed and control; $\mathrm{F}=43.12, p(\mathrm{~F})<0.0001$ ). The stressed bad-learner group showed a similar pattern of onset latency over the days to that of the stressed good-learners, with a higher onset latency on day 5 compared to day $4(p<0.01)$. In the comparison of the stressed and control bad-learners, the former showed a higher onset latency compared to the latter only on day 5 ( $p<0.01$ ) (Figure 3(b)). 


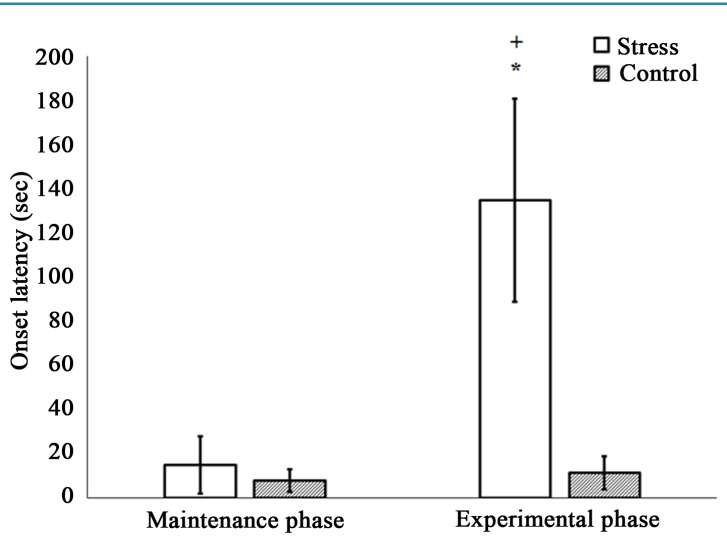

(a)

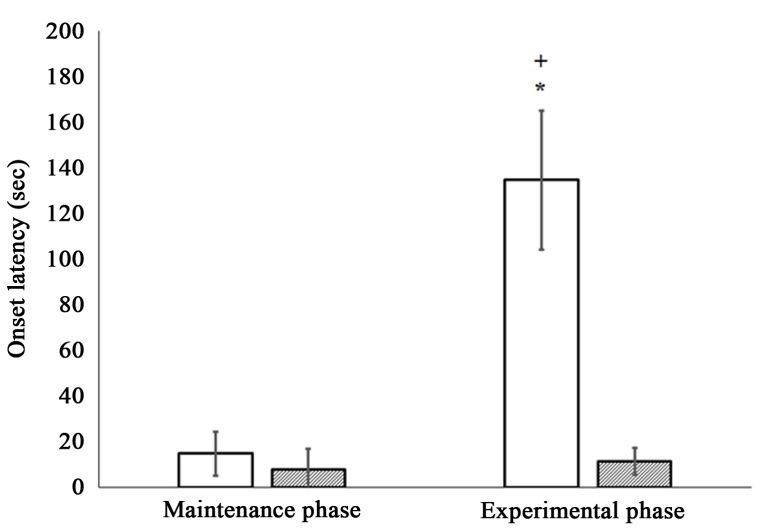

(b)

Figure 3. Mean \pm 2 SE of onset latency during the non matching-to-sample task in a T-maze during the maintenance phase (day 4), and experimental phase (day 5), performed by (a) both stressed and control good-learners ( $\mathrm{n}=6$ /group); and (b) both stressed and control bad-learners ( $\mathrm{n}=10$ /group). ${ }^{*} p<0.01$ compared to the stressed group on day 4 ; ${ }^{+} p<0.01$ compared to the control group on day 5.

\subsection{Comparison between Series 1 and 2 on Day 5 (Stressed Groups)}

\subsubsection{Percentage of Correct Responses}

The stressed good-learners group showed no significant differences in the median of percentage of correct responses in series $1(94.0 \pm 21.75)$ compared to series $2(30 \pm 71.4)$ on day $5(\mathrm{~W}=0.0 ; p(\mathrm{~W})=0.0579)$. Only the stressed bad-learners showed a higher percentage of correct responses in series 1 (100 \pm 12.5$)$ compared to series $2(66.67 \pm 24.17)$ on day $5(\mathrm{~W}=0.0 ; p(\mathrm{~W})=0.0057)$.

\subsubsection{Onset Latency}

Both the stressed bad- and good-learners groups showed a higher onset latency in series 1 [(good-learners: $134.562 \mathrm{sec} \pm 46.006$; bad-learners: $132.056 \mathrm{sec} \pm 30.554)$ ], compared to series 2 [(good-learners: 15.913 sec \pm 14.46; bad learners: $13.075 \mathrm{sec} \pm 8.006$ )] on day 5 (good-learners: $\mathrm{t}=4.32, p(\mathrm{t})=0.0076$; bad-learners: $\mathrm{t}=6.75$, $p(\mathrm{t})=0.0001)$.

\section{Discussion}

This article describes a differential effect of acute stress caused by cold water immersion (CWI) on sexual motivation and visuospatial working memory in a sexually-motivated task performed by male rats. While acute stress appeared to improve the performance of the male rats on the working memory task, an evident decrease on sexual motivation was observed.

As in previous studies [18] [20], the paradigm used in this paper (nonmatching-to-sample working memory task using a T-maze) made it possible to assess working memory on a sexually-motivated task, because during the test run (the condition in which working memory is exhibited) the rat must be able to "remember" the arm visited in the sample run in order to enter the opposite arm during the test run and thus obtain the sexual reward (one intromission). The behavioral data reported in this work agree with previous studies which showed that sexual behavior is an efficient reinforcer in promoting learning and working memory processes [15]-[18] [20].

In this work, neither the stressed nor the control good-learners showed any changes in the percentage of correct responses performed during the experimental phase (day 5) compared to the maintenance phase (day 4); which demonstrates that once a male rat achieves good level of learning on the sexually-motivated task, its performance is not affected by the acute stress induced by CWI.

Only the stressed bad-learners showed a higher percentage of correct responses on day 5 (experimental phase) compared to day 4 (maintenance phase). Although it is probable that this improvement in the number of correct responses of working memory could result from experience with the task, as reported in other studies [31], it is well-known that stress is associated with an increase in corticosterone levels that affects the functionality of brain structures - such as the prefrontal cortex (PFC) - involved in the processing of several executive functions. Sánchez-Santed et al. [31] showed that PFC lesions affect working memory in male rats, but only transiently, 
such that the effect quickly diminishes with practice. These facts were interpreted by the authors as plastic phenomena mediated by NMDA receptors in the PFC; receptors that play a pivotal role in glutamatergic transmission, which controls excitation in the PFC.

In this study, the behavioral performance of the stressed good-learners and stressed bad-learners before applying the stressor was clearly different. However, after the stress treatment, both groups showed a percentage of correct responses above $80 \%$; i.e., the stressed good-learner rats maintained their correct execution, while the stressed bad-learners increased their percentage of correct responses, so that they showed a similar performance to that of the good-learners after acute stress caused by CWI. Furthermore, only the stressed bad-learner rats showed a higher percentage of correct responses compared to the control rats; indicating that, in effect, the acute stress caused by CWI improved the performance of the bad-learners on the sexually-motivated task (working memory).

It has been suggested that the mechanism through which acute stress (by CWI) facilitates working memory could be increased post-synaptic glutamatergic transmission in the pyramidal cells of the PFC as a consequence of an increase of corticoid hormones [8] [9]. Yuen et al. [8] reported data that agree with this suggestion. They assessed the effect of acute stress on working memory and found that stressed rats showed a higher percentage of correct responses after experiencing acute stress. In a later study, those authors [9] found similar behavioral data after stress treatment, which they associated with plastic phenomena in the pyramidal cells of the PCF by means of an improved post-synaptic glutamatergic transmission mediated by corticoid hormones. Thus, considering that the PFC is an important structure in the modulation of working memory, it is probable that the increased levels of corticosterone triggered by the stress situation could activate glutamatergic transmission in the PFC and thus facilitate the performance of working memory in the stressed bad-learner subjects.

Other studies, however, do not concur with our results, as they suggest that acute stress impairs working memory [4] [6] [32]. Those studies have suggested that the negative effect of acute stress on working memory is mediated by the interaction of glucocorticoids and adrenergic mechanisms (for a review see [33]), since administration of adrenergic receptor antagonists facilitates working memory on a delayed task [34]. The suggestion that glucocorticoids have a negative effect on working memory was proposed based on data obtained in paradigms that used food as the reward [4] [6] [32]. In contrast, the rewarding effect of sexual behavior is mediated by different neurotransmission and hormonal systems than those activated by food [35]. The sexual behavior is modulated by a negative feedback system between the hypothalamus-pituitary-adrenal axis (involved in stress response) and the hypothalamus-pituitary-gonads axis (involved in the motivation and performance of sexual behavior) that produces an antagonist effect between the glucocorticoids and such gonadal hormones as testosterone [21]. Considering that testosterone levels in male rats increase during sexual behavior [21], it is probable that while the male rats are executing the sexually-motivated working memory task, the functioning of both axes could interact and, as a result of the increase in testosterone levels, decrease corticosteroid levels to a point at which working memory improves after experiencing acute stress.

Traditionally, the sexual motivation of male rats during sexual interaction has been measured by such parameters as mount latency, intromission latency and ejaculation latency [21]-[25]; whereas ex-copula, several paradigms have been used, including performance in mazes with a sexual reward in which onset latency has been the main parameter considered [16] [36]. In the present work, the stressed groups (both good- and bad-learners) presented higher onset latencies on day 5 (after stress treatment) than in the maintenance phase (day 4). Furthermore, the comparison between the stressed and control groups (both bad- and good-learners) showed that only the stressed rats presented a higher onset latency and intromission latency; results which demonstrate that acute stress caused by CWI decreased the rats' sexual motivation to perform the working memory task.

These results agree with several previous studies that have shown that sexual motivation can be affected by stress when the stressor is administered in an acute form [21]-[25] [37] [38]. It has been reported that the CWI paradigm increases corticosterone concentrations in the plasma [21]. As mentioned above, corticosterone exerts a negative effect on testosterone levels and, as a result, male rats present increased mount, intromission and ejaculation latencies, as well as decreased hit rates [26]. Thus, it is probable that in this work, a similar hormonal mechanism could explain the decreased sexual motivation observed in the subjects of both stressed groups.

One particularly interesting result is that both the stressed bad- and good-learners groups showed an increased onset latency only in series 1 (i.e., immediately after exposure to stress), compared to series 2 (i.e., after the males reached ejaculation). These data confirm the anxiolytic-like effect that has been shown to be exerted by the ejaculation response in male rats [39] [40]. 


\section{Conclusion}

In conclusion, the behavioral data of this paper show, on one hand, that acute stress caused by CWI exerts a facilitating effect on working memory (non-matching-test) in sexually-motivated male rats, and, on the other hand, that acute stress exerts a negative effect on the sexual motivation required to perform the aforementioned working memory task. It is probable that the facilitating effect of acute stress on working memory results from the activation of glutamatergic transmission in the PFC, mediated by corticoid hormones, as other authors have suggested [8] [9], whereas the negative effect on sexual motivation could result from decreased testosterone levels mediated by the corticosterone secreted during exposure to stress [26].

\section{References}

[1] Stratakis, C.A. and Chrousos, G.P. (1995) Neuroendocrinology and Pathophysiology of the Stress System. Annals of the New York Academy of Sciences, 771, 1-18. http://dx.doi.org/10.1111/j.1749-6632.1995.tb44666.x

[2] Dhabhar, F.S., Malarkey, W.B., Neri E. and McEwen, B.S. (2012) Stress-Induced Redistribution of Immune Cellsfrom Barracks to Boulevards to Battlefields: A Tale of Three Hormones-Curt Richter Award Winner. Psychoneuroendocrinology, 37, 1345-1368. http://dx.doi.org/10.1016/j.psyneuen.2012.05.008

[3] Tafet, G.E. and Bernardini, R. (2003) Psychoneuroendocrinological Links between Chronic Stress and Depression. Progress in Neuro-Psychopharmacology Biological Psychiatry, 27, 893-903. http://dx.doi.org/10.1016/S0278-5846(03)00162-3

[4] Butts, K.A., Ewinberg, J., Young, A.H. and Phillips, A.G. (2011) Glucocorticoid Receptors in the Prefrontal Cortex Regulate Stress-Evoked Dopamine Efflux and Aspects of Executive Function. PNAS, 18, 459-464. http://dx.doi.org/10.1073/pnas.1111746108

[5] Murphy, B.L., Arsten, A.F.T., Goldman-Rakic, P.S. and Roth, R.H. (1996) Incresead Dopamine Turnover in the Prefrontal Cortex Impairs Spatial Working Memory Performance in Rats and Monkeys. PNAS, 93, 1325-1329. http://www.pnas.org/content/93/3/1325.full.pdf http://dx.doi.org/10.1073/pnas.93.3.1325

[6] Devilbiss, D.M., Jenison, R.L. and Berridge, C.W. (2012) Stress-Induce Impairment of a Working Memory Task: Role of Spiking Rate and Spiking History Predicted Discharge. PLOS Computational Biology, 8, 1-14. http://dx.doi.org/10.1371/journal.pcbi.1002681

[7] Sandi, C., Loscertales, M. and Guaza, C. (1997) Experience-Dependent Facilitating Effect of Corticosterone on Spatial Memory Formation in the Water Maze. European Journal of Neuroscience, 9, 637-642. http://dx.doi.org/10.1111/j.1460-9568.1997.tb01412.x

[8] Yuen, E.Y., Liu, W., Karatsoreos, I.N., Feng, J., McEwen, B.S. and Yan, Z. (2009) Acute Stress Enhances Glutamatergic Transmission in Prefrontal Cortex and Facilitates Working Memory. PNAS, 106, 14075-14079. http://dx.doi.org/10.1073/pnas.0906791106

[9] Yuen, E.Y., Liu, W., Karatsoreos, I.N., Ren, Y., Feng, J., McEwen, B.S. and Yan, Z. (2011) Mechanisms for Acute Stress-Induced Enhancement of Glutamatergic Transmission and Working Memory. Molecular Psychiatry, 16, 156170. http://dx.doi.org/10.1038/mp.2010.50

[10] Goldman-Rakic, P.S. (1996) Regional and Cellular Fractionation of Working Memory. PNAS, 93, 13473-13480. http://www.pnas.org/content/93/24/13473.full.pdf http://dx.doi.org/10.1073/pnas.93.24.13473

[11] Petrides, M. (2005) Lateral Prefrontal Cortex: Architectonic and Functional Organization. Philosophical Transactions of the Royal Society B: Biological Sciences, 360, 781-795. http://dx.doi.org/10.1098/rstb.2005.1631

[12] Gisquet-Verrier, P. and Delatour, B. (2006) The Role of the Rat Prelimbic/Infralimbic Cortex in Working Memory: Not Involved in the Short-Term Maintenance but in Monitoring and Processing Functions. Neuroscience, 141, 585-596. http://dx.doi.org/10.1016/j.neuroscience.2006.04.009

[13] Kagan, J. (1955) Differential Reward Value of Incomplete and Complete Sexual Behavior. Journal of Comparative and Physiological Psychology, 48, 59-64. http://dx.doi.org/10.1037/h0043461

[14] Whalen, R.E. (1961) Effects of Mounting without Intromission and Intromission without Ejaculation on Sexual Behavior and Maze Learning. Journal of Comparative and Physiological Psychology, 54, 409-415. http://dx.doi.org/10.1037/h0046385

[15] Ågmo, A. (1999) Sexual Motivation-An Inquiry into Events Determining the Occurrence of Sexual Behavior. Behavioural Brain Research, 105, 129-150. http://dx.doi.org/10.1016/S0166-4328(99)00088-1

[16] Hernández-González, M., Prieto-Beracoechea, C.A., Arteaga-Silva, M. and Guevara, M.A. (2007) Different Functio- 
nality of the Medial and Orbital Prefrontal Cortex during a Sexually Motivated Task in Rats. Physiology \& Behavior, 90, 450-458. http://dx.doi.org/10.1016/j.physbeh.2006.10.006

[17] Tenk, C.M., Wilson, H., Zhang, Q., Pitchers, K.K. and Coolen, L.M. (2009) Sexual Reward in Male Rats: Effects of Sexual Experience on Conditioned Place Preferences Associated with Ejaculation and Intromissions. Hormones and Behavior, 55, 93-97. http://dx.doi.org/10.1016/j.yhbeh.2008.08.012

[18] Hernández-González, M., Almanza-Sepúlveda, M.L., Olvera-Cortés, M.E., Gutiérrez-Guzmán, B.E. and Guevara, M.A. (2012) Prefrontal Electroencephalographic Activity during the Working Memory Processes Involved in a Sexually Motivated Task in Male Rats. Experimental Brain Research, 221, 143-153. http://dx.doi.org/10.1007/s00221-012-3155-z

[19] Beach, F.A. and Jordan, L. (1956) Effects of Sexual Reinforcement upon the Performance of Male Rats in a Straight Runway. Journal of Comparative and Physiological Psychology, 49, 105-111. http://dx.doi.org/10.1037/h0046471

[20] Almanza Sepúlveda, M.A., Gutiérrez Guzmán, B.E., Olvera Cortés, M.E., Guevara, M.A. and Hernández-González, M. (2010) Modelo de memoria de trabajo en ratas macho sexualmente motivadas. Scientia-CUCBA, 12, 39-49.

[21] Retana-Márquez, S., Bonilla-Jaime, H., Vázquez-Palacios, G., Martínez-García, R. and Velázquez-Moctezuma, J. (2003) Changes in Masculine Sexual Behavior, Corticosterone and Testosterone in Response to Acute and Chronic Stress in Male Rats. Hormones and Behavior, 44, 327-337. http://dx.doi.org/10.1016/j.yhbeh.2003.04.001

[22] Larsson, K. (1963) Non-Specific Stimulation and Sexual Behavior in the Male Rat. Behavior, 20, 110-114. http://dx.doi.org/10.1163/156853963X00239

[23] Barfield, R. and Sachs, B. (1968) Sexual Behavior Stimulation by Painful Electrical Shock to Skin in Male Rats. Science, 161, 192-395. http://dx.doi.org/10.1126/science.161.3839.392

[24] Menéndez-Patterson, A., Flores-Lozano, J.A., Fernández, S. and Marín, B. (1978) Stress and Sexual Behavior in Male Rats. Physiology \& Behavior, 24, 403-406. http://dx.doi.org/10.1016/0031-9384(80)90106-7

[25] Retana-Márquez, S., Domínguez-Salazar, E. and Velázquez-Moctezuma, J. (1996) Effect of Acute and Chronic Stress on Masculine Sexual Behavior in the Rat. Psychoneuroendocrinology, 21, 39-50. http://dx.doi.org/10.1016/0306-4530(95)00029-1

[26] Rocher, C., Spedding, M., Munoz, C. and Jay, T.M. (2004) Acute Stress-Induced Changes in Hippocampal/Prefrontal Circuits in Rats: Effects of Antidepressants. Cerebral Cortex, 14, 224-229. http://dx.doi.org/10.1093/cercor/bhg122

[27] Diamond, D.M., Fleshner, M., Ingersoll, N. and Rose, G.M. (1996) Psychological Stress Impairs Spatial Working Memory: Relevance to Electrophysiological Studies of Hippocampal Function. Behavioral Neuroscience, 110, 661-672. http://dx.doi.org/10.1037/0735-7044.110.4.661

[28] McEwen, B.S. and Chattarji, S. (2004) Molecular Mechanisms of Neuroplasticity and Pharmacological Implications: The Example of Tianeptine. European Neuropsychopharmacology, 14, 497-502. http://dx.doi.org/10.1016/j.euroneuro.2004.09.008

[29] Frajese, G., Lazzari, R., Magnani, A., Moretti, C., Sforza, V. and Nerozzi, D. (1990) Neurotransmitter, Opiodergic System, Steroid-Hormone Interaction and Involvement in the Replacement Therapy of Sexual Disorders. The Journal of Steroid Biochemistry and Molecular Biology, 37, 411-419. http://dx.doi.org/10.1016/0960-0760(90)90492-4

[30] Guevara, M.A., Amezcua, C.C., Hernández-González, M. and Sanz, A. (2012) Sexy Mater: programa computacional para el registro y análisis de conductas sexuales y maternales en roedores. Neurobiología, Revista Electrónica, 12, 113.

[31] Sánchez-Santed, F., de Bruin, J.C.P., Heinsbroek, R.P.W. and Verwer, R.W.H. (1997) Spatial Delayed Alteration of Rats in a T-Maze: Effects of Neurotoxic Lesions of the Medial Prefrontal Cortex and of T-Maze Rotations. Behavioural Brain Research, 84, 73-79. http://dx.doi.org/10.1016/S0166-4328(97)83327-X

[32] Arnsten, A.F.T. and Goldman-Rakic, P.S. (1998) Noise Stress Impairs Prefrontal Cortical Cognitive Function in Monkeys. Archives of General Psychiatry, 55, 362-368. http://dx.doi.org/10.1001/archpsyc.55.4.362

[33] Quervain, D.J.F., Aerni, A., Schelling, G. and Roozendaal, B. (2009) Glucocorticoids and the Regulation of Memory in Health and Disease. Frontiers in Neuroendocrinology, 30, 358-370. http://dx.doi.org/10.1016/j.yfrne.2009.03.002

[34] Roozendaal, B., McReynolds, J.R. and McGaugh, J.L. (2004) The Basolateral Amygdala Interacts with the Medial Prefrontal Cortex in Regulating Glucocorticoid Effects on Working Memory Impairment. Journal of Neuroscience, 24, 1385-1392. http://dx.doi.org/10.1523/JNEUROSCI.4664-03.2004

[35] Mani, S.K., Allen, J.M., Clark, J.H., Blaustein, J.D. and O’Malley, B.W. (1994) Convergent Pathways for Steroid Hormone- and Neurotransmitter-Induced Rat Sexual Behavior. Science, 265, 1246-1249. http://dx.doi.org/10.1126/science.7915049

[36] Paredes, R.G. (2009) Evaluating the Neurobiology of Sexual Reward. ILAR Journal, 50, 15-27. http://dx.doi.org/10.1093/ilar.50.1.15 
[37] Coddington, E., Lewis, C., Rose, J.D. and Moore, F.L. (2007) Endocannabinoids Mediate the Effects of Acute Stress and Corticosterone on Sex Behavior. Endocrinology, 148, 493-500. http://dx.doi.org/10.1210/en.2006-0740

[38] Dickens, M.J., Cornil, C.A. and Balthazart, J. (2011) Acute Stress Differentially Affects Aromatase Activity in Specific Brain Nuclei of Adult Male and Female Quail. Endocrinology, 152, 4242-4251. http://dx.doi.org/10.1210/en.2011-1341

[39] Rodríguez-Manzo, G., López-Rubalcava, C. and Fernández-Guasti, A. (1999) Anxiolytic-Like Effect of Ejaculation under Various Sexual Behavior Conditions in the Male Rat. Physiology \& Behavior, 67, 651-657. http://dx.doi.org/10.1016/S0031-9384(99)00119-5

[40] Fernández-Guasti, A., Roldán-Roldán, G. and Saldívar, A. (1989) Reduction in Anxiety after Ejaculation in the Rat. Behavioural Brain Research, 32, 23-29. http://dx.doi.org/10.1016/S0166-4328(89)80068-3 